\title{
Observation of extremely strong shock waves in solids launched by petawatt laser heating
}

K. L. Lancaster, A. P. L. Robinson, J. Pasley, P. Hakel, T. Ma, K. Highbarger, F. N. Beg, S. N. Chen, R. L. Daskalova, R. R. Freeman, J. S. Green, H. Habara, P. Jaanimagi, M. H. Key, J. King, R. Kodama, K. Krushelnick, H. Nakamura, M. Nakatsutsumi, A. J. MacKinnon, A. G. MacPhee, R. B. Stephens, L. Van Woerkom, and P. A. Norreys

Citation: Physics of Plasmas 24, 083115 (2017); doi: 10.1063/1.5000064

View online: https://doi.org/10.1063/1.5000064

View Table of Contents: http://aip.scitation.org/toc/php/24/8

Published by the American Institute of Physics

\section{Articles you may be interested in}

Controlling femtosecond-laser-driven shock-waves in hot, dense plasma

Physics of Plasmas 24, 072702 (2017); 10.1063/1.4990059

Fast ion acceleration in a foil plasma heated by a multi-picosecond high intensity laser

Physics of Plasmas 24, 073111 (2017); 10.1063/1.4990703

Interaction of a highly radiative shock with a solid obstacle

Physics of Plasmas 24, 082707 (2017); 10.1063/1.4996010

Monoenergetic ion beam acceleration from transversely confined near-critical plasmas by intense laser pulses Physics of Plasmas 24, 093108 (2017); 10.1063/1.4999506

Astrophysical particle acceleration mechanisms in colliding magnetized laser-produced plasmas Physics of Plasmas 24, 092901 (2017); 10.1063/1.4993204

Ultrafast multi-MeV gamma-ray beam produced by laser-accelerated electrons Physics of Plasmas 24, 093104 (2017); 10.1063/1.4996020

\section{PHYSICS TODAY}

MANAGER'S GUIDE

WHITEPAPERS

\section{READ NOW}

PRESENTED BY

Accelerate R\&D with Multiphysics Simulation $\checkmark \subset \bigcirc M S O L$ 


\title{
Observation of extremely strong shock waves in solids launched by petawatt laser heating
}

\author{
K. L. Lancaster, ${ }^{1}$ A. P. L. Robinson, ${ }^{2}$ J. Pasley, ${ }^{1,2}$ P. Hakel, ${ }^{3}$ T. Ma, ${ }^{4}$ K. Highbarger, ${ }^{5}$ \\ F. N. Beg, ${ }^{6}$ S. N. Chen, ${ }^{7}$ R. L. Daskalova, ${ }^{5}$ R. R. Freeman, ${ }^{5}$ J. S. Green, ${ }^{2}$ H. Habara, ${ }^{8,9}$ \\ P. Jaanimagi, ${ }^{10}$ M. H. Key, ${ }^{4}$ J. King, ${ }^{6}$ R. Kodama, ${ }^{8,9,11}$ K. Krushelnick, ${ }^{12} \mathrm{H}$. Nakamura, ${ }^{8}$ \\ M. Nakatsutsumi, ${ }^{13}$ A. J. MacKinnon, ${ }^{4}$ A. G. MacPhee,${ }^{4}$ R. B. Stephens, ${ }^{14}$ \\ L. Van Woerkom, ${ }^{5}$ and P. A. Norreys ${ }^{2,15}$ \\ ${ }^{1}$ Department of Physics, York Plasma Institute, University of York, York YO10 5DQ, United Kingdom \\ ${ }^{2}$ STFC Rutherford Appleton Laboratory, Chilton, Oxon OX11 0QX, United Kingdom \\ ${ }^{3}$ Los Alamos National Laboratory, Los Alamos, New Mexico 87545, USA \\ ${ }^{4}$ Lawrence Livermore National Laboratory, P.O. Box 808, Livermore, California 94550, USA \\ ${ }^{5}$ Department of Physics, Ohio State University, Columbus, Ohio 43210-1117, USA \\ ${ }^{6}$ University of California San Diego, 9500 Gilman Drive 0411, La Jolla, California 92093-0411, USA \\ ${ }^{7}$ LULI, École Polytechnique, route de Saclay, 91128 Palaiseau Cedex, France \\ ${ }^{8}$ Graduate School of Engineering, Osaka University, Suita, Osaka 565087, Japan \\ ${ }^{9}$ Photon Pioneers Center, Osaka University, Suita, Osaka 565087, Japan \\ ${ }^{10}$ Laboratory for Laser Energetics (LLE), University of Rochester, 250E. River Rd., Rochester, \\ New York 14623, USA \\ ${ }^{11}$ Institute Academic Initiatives, Osaka University, Suita, Osaka 5650871, Japan \\ ${ }^{12}$ University of Michigan, Ann Arbor, Michigan 48109-2099, USA \\ ${ }^{13}$ European XFEL GmbH, Holzkoppel 4, 22869 Schenefeld, Germany \\ ${ }^{14}$ General Atomics, P.O. Box 86508, San Diego, California 92186-5608, USA \\ ${ }^{15}$ Department of Physics, Clarendon Laboratory, University of Oxford, Oxford OX1 3PU, United Kingdom
}

(Received 28 October 2016; accepted 10 August 2017; published online 25 August 2017)

Understanding hydrodynamic phenomena driven by fast electron heating is important for a range of applications including fast electron collimation schemes for fast ignition and the production and study of hot, dense matter. In this work, detailed numerical simulations modelling the heating, hydrodynamic evolution, and extreme ultra-violet (XUV) emission in combination with experimental XUV images indicate shock waves of exceptional strength (200 Mbar) launched due to rapid heating of materials via a petawatt laser. We discuss in detail the production of synthetic XUV images and how they assist us in interpreting experimental XUV images captured at $256 \mathrm{eV}$ using a multi-layer spherical mirror. Published by AIP Publishing. [http://dx.doi.org/10.1063/1.5000064]

\section{INTRODUCTION}

Strong, radiating shock waves are associated with the most violent processes in nature, such as supernovae, ${ }^{1}$ black hole mergers, ${ }^{2}$ and gamma-ray burst sources. ${ }^{1,3}$ Shock waves may even be critical to the generation of protogalatic seed magnetic fields. ${ }^{4}$ Shock waves play a crucial role in conventional hot spot inertial confinement fusion $(\mathrm{ICF})^{5}$ and alternative schemes such as shock ${ }^{6}$ and fast ${ }^{7}$ ignition. Producing such shock waves in the laboratory has long been one of the objectives of high power laser interaction experiments. ${ }^{8-11}$ The strongest shock waves that can be produced in the laboratory are those that result from the interaction of an ultrahigh intensity $\left(>10^{18} \mathrm{~W} \mathrm{~cm}^{-2} \mu \mathrm{m}^{2}\right)$, high energy $(>100 \mathrm{~J})$ laser pulse with a dense target. In these interactions, solids are isochorically heated to temperatures in the range of $0.01-0.8 \mathrm{keV},{ }^{12}$ thus reaching transient pressures approaching $1 \mathrm{Gbar}$. In comparison, typical drive pressures achieved in the NIF ignition experiments peak above 100 Mbar. ${ }^{13}$ Such an interaction forms an integral part of the fast ignition approach to inertial fusion, ${ }^{7,14,15}$ and as such an understanding of the formation of such shock waves is important for the further development of this approach to fusion. ${ }^{16}$ The presence of such ultra-strong shock waves, which may have pressures of many hundreds of Mbar or more, can be inferred from spectroscopic measurements. ${ }^{17}$

In this paper, we report the first images indicating such shock waves in dense materials, formed from the extreme ultra-violet (XUV) emission in the dense plasma. The rapidly decaying nature of the shock wave as it propagates through the plasma, coupled with the narrow acceptance wavelength of the imager employed, produces a temporally gated ringlike image of the expanding cylindrical shock front. This shock front is centred upon the region in which a beam of relativistic electrons, generated by the laser-plasma interaction, produces intense Ohmic heating for $<1$ ps. ${ }^{12,18}$ Based on simulations, we infer that the pressure associated with this shock front at the time it is imaged is approximately 200 Mbar. The pressure earlier in time is thought to exceed 1 Gbar.

A fast electron transport code was used to predict target heating patterns in thin solid foils $(8 \mu \mathrm{m} \mathrm{CH})$. The subsequent evolution of the target on the multi-ps timescale was modelled using the radiation hydrodynamics code $\mathrm{h} 2 \mathrm{~d}$, and the data from this were post-processed using the collisionalradiative atomic kinetics and spectral code SPECT3D, ${ }^{19}$ to generate synthetic XUV images. These images predict a distinct ring-like feature in the XUV due to the shock wave 
launched by the strong explosion of the heated region. The central region is heated supersonically by relativistic electron propagation and associated return currents drawn in the background plasma. These return currents, which are driven by the requirement to locally conserve charge, result in strong Ohmic heating of the dense plasma. Significant hydrodynamic motion only ensues after the heating process has completed, due to the very short (600 fs) duration of the laser pulse. XUV images obtained experimentally record a strong ring-like emission feature which correlates with the shock position around $20 \mathrm{ps}$ after the laser pulse. The fully timeintegrated imager is effectively gated purely by the physical behaviour of the system, as the emission in the narrow bandwidth of the imager is only significant for a few picoseconds, thereby capturing the shock wave at a particular moment in time.

Work by Robinson et al. ${ }^{20}$ shows that it is possible to use resistively structured targets, such as a wire of higher resistivity buried in a lower resistivity substrate, as a driver for hydrodynamic phenomena. The innovative diagnostic approach which has been developed as a part of this study may allow us to observe the resulting hydrodynamics in such targets. More generally, it may also enable a wide range of hydrodynamic phenomena that are launched by fast electron heating to be observed and studied quantitatively.

\section{THEORETICAL AND NUMERICAL STUDIES}

In order to drive a strong cylindrical shock wave, a sufficiently columnar heating pattern must be achieved during the interaction of a PW laser pulse with a simple foil. The ZEPHYROS 3D hybrid code was used to understand under which conditions this was possible. ZEPHYROS ${ }^{21,22}$ is a 3D particle hybrid code, mainly based on the methods of Davies. $^{23}$ The target studied was a homogeneous $8 \mu \mathrm{m}$ thick $\mathrm{CH}$ foil. A fast electron beam was injected that modelled irradiation by a 600 fs laser pulse with a $10 \mu \mathrm{m}$ FWHM spot and a FWHM intensity of $5 \times 10^{20} \mathrm{~W} \mathrm{~cm}^{-2}$. The following assumptions were made in this modelling: $20 \%-30 \%$ laser to fast electron energy conversion efficiency, ${ }^{24,25}$ exponential energy distribution with an average energy determined by ponderomotive scaling, and a characteristic angular divergence of $25^{\circ}-45^{\circ}$ for the fast electrons. ${ }^{26}$ The resistivity curve used for the $\mathrm{CH}$ target is the one used by Davies in Ref. 23. Reflective boundaries were used throughout. The heating patterns after 1 ps typically showed heating right through the thickness of the target, and the variation with depth could be reasonably well fit by

$$
T=(A \exp [-x / d]+B) \exp \left[-r^{2} / 2 L^{2}\right],
$$

where $x$ is in $\mu \mathrm{m}, d=4 \mu \mathrm{m}, A=0.8-2 \mathrm{keV}, B=0.2-0.6 \mathrm{keV}$, and $L$ typically about $10 \mu \mathrm{m}$ depending on the precise assumptions made in the transport simulation. An example of one of the results of these calculations is shown in Fig. 1.

Such a heating pattern should be sufficiently columnar to launch a strong cylindrical shock wave, and this was confirmed by $2 \mathrm{D}$ radiation hydrodynamics simulations in which a uniform $8 \mu \mathrm{m}$ slab of $\mathrm{CH}$ was initialized with the temperature

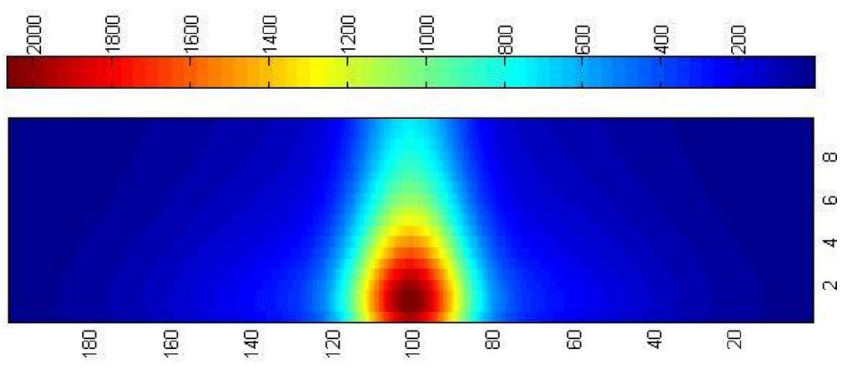

FIG. 1. Temperature profile from a 3D ZEPHYROS fast electron transport simulation showing the background temperature in $\mathrm{eV}$ (red corresponding to $2000 \mathrm{eV}$ ) at $1 \mathrm{ps}$ in the $x-y$ midplane of the box.

profile obtained from the fast electron transport calculations [Eq. (1)]. These simulations were carried out using h2d, ${ }^{27} \mathrm{a}$ 2D $r-z$ Lagrangian radiation hydrodynamics code. The "baseline" case that was used was $A=2 \mathrm{keV}, B=0.6 \mathrm{keV}$, and $L=10 \mu \mathrm{m}$. In general, the simulations showed that the heated region would strongly cavitate and cause strong transverse compression, leading to a strong shock wave propagating out from the central heated region for tens of ps after the interaction. The results of the baseline simulation, in terms of the mass density at $20 \mathrm{ps,}$ are shown in Fig. 2. In this figure, the cavitation of the heated region can be seen between $r=0$ and $20 \mu \mathrm{m}$ (where zero is the centre of the heated region), and the compressed region can be seen at $r \approx 20 \mu \mathrm{m}$. The initial pressure of the heated region is close to 1 Gbar, and the pressure of the shock wave is still $>100$ Mbar even after the shock wave has propagated $10 \mathrm{~s}$ of $\mu \mathrm{m}$ outward. The combination of the transport simulation and the radiation hydrodynamic simulations leads to the conclusion that a strong cylindrical shock front should be launched in experimentally accessible interactions with thin foils.

The next consideration is whether or not this would lead to a detectable signal in commonly used plasma diagnostics. In this paper, we consider the possibility of using XUV imaging to observe such shocks.

In order to ascertain whether observing signatures of strong shocks via XUV imaging was possible, the output of the radiation hydrodynamics simulations was post-processed

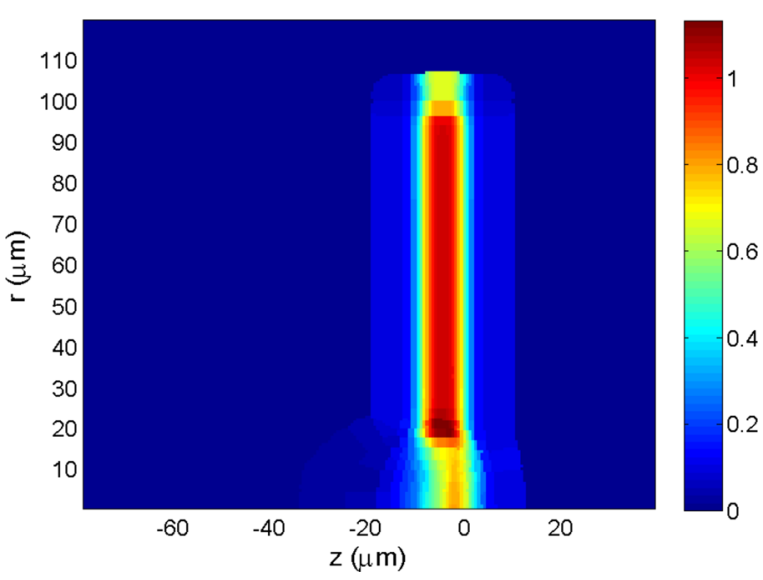

FIG. 2. Mass density profile (in $\mathrm{g} \mathrm{cm}^{-3}$; red corresponding to $1 \mathrm{~g} \mathrm{~cm}^{-3}$ ) at $20 \mathrm{ps}$ from the baseline $\mathrm{h} 2 \mathrm{~d}$ radiation hydrodynamics simulation. The cavitation of the heated region can be seen from $r=0-20 \mu \mathrm{m}$ in the foil where 0 is the centre of the heated region, and the compressed region lies at around $r=20 \mu \mathrm{m}$. 
using the SPECT3D code. ${ }^{19}$ This was used to generate "synthetic" time-integrated XUV images, specifically the $\mathrm{XUV}$ emission at $256 \mathrm{eV}$ that would be detected using the XUV imaging system available for experiments (i.e., looking at the target rear surface close to normal with multi-layer mirrors with a magnification of $\approx 10-12$ and a spatial resolution of $\approx 10 \mu \mathrm{m}$.). The synthetic image that is obtained from the baseline case is shown in Fig. 3. This shows a bright ring of emission associated with the radially expanding shock front. The image is strongly correlated with a particular time in the $\mathrm{h} 2 \mathrm{~d}$ simulation at which the shock front is at the same radius and the shock pressure is approximately $200 \mathrm{Mbar}$. Although the target opacity is not negligible, there is sufficient transparency to allow clear observation of the emission from this region. From this, it was concluded that the transverse explosion of the heated region would lead to a clear signal in time-integrated XUV measurements, which directly corresponds to the emission from a strong outwardly expanding cylindrical shock front at a time approximately $20 \mathrm{ps}$ after the laser-solid interaction.

The result can be understood by considering the limit of an optically thin foil and then considering only the free-free emission process. At a particular photon energy, $h \nu$, this will vary $\propto Z n_{e}^{2} e^{-h \nu / k_{B} T} / \sqrt{k_{B} T}$ (neglecting the Gaunt factor). At a fixed density, this function has a weak maximum at $T=512 \mathrm{eV}$ for $h \nu=256 \mathrm{eV}$ and only falls sharply below about $200 \mathrm{eV}$. If one now considers the effect that the $n_{e}^{2}$ scaling has on the emission as the heated region cavitates and compresses the surrounding material, then one can see that the dominant emission can actually come from the slightly cooler shell of the compressed material, rather than the hotter but decompressed centre. In reality, the emission from the cooler region will be further enhanced by the carbon atoms retaining a substantial bound electron population.

\section{UNDERSTANDING EXPERIMENTAL STUDIES}

This theoretical and numerical study predicts the possibility of clearly observing the transverse compression wave

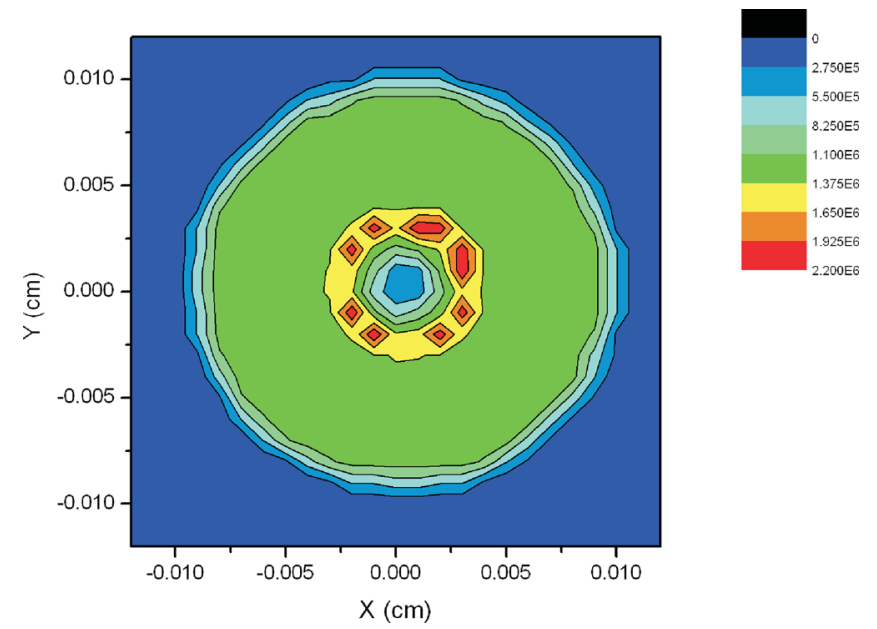

FIG. 3. A synthetic time-integrated XUV image obtained by post-processing the baseline radiation-hydrodynamic simulation output using the SPECT3D code (color scale is in arbitrary units). The imager is assumed to look at the target's rear surface along the target normal. under conditions that closely resemble an experiment that was carried out using the Vulcan petawatt laser. The Vulcan $\mathrm{PW}^{28}$ delivered up to $300 \mathrm{~J}$ of $\lambda=1.05 \mu \mathrm{m}$ light onto the target in a pulse duration of $700 \mathrm{fs}$. The laser was focused onto the target using an $\mathrm{F} / 3$ off axis parabolic mirror to a spot size of $7 \mu \mathrm{m}$ in diameter. Approximately $20 \%$ of the energy was contained within the central focal spot giving peak intensities up to $2.5 \times 10^{20} \mathrm{~W} \mathrm{~cm}^{-2}$. The intensity contrast ratio of the ASE to the peak power of the laser was $5 \times 10^{-8}, 1.5 \mathrm{~ns}$ ahead of the interaction pulse. ${ }^{29}$ The targets consisted of either $10 \mu \mathrm{m}$ of $\mathrm{CH}$ with a $50 \mathrm{~nm}$ layer of $\mathrm{Al}$ on the rear surface or a front layer of $\mathrm{CH}$ of thicknesses $4 \mu \mathrm{m}$, a thin tracer layer of $\mathrm{Al}(0.2 \mu \mathrm{m})$, and a layer of $4 \mu \mathrm{m} \mathrm{CH}$ at the rear.

Extreme ultra-violet radiation (XUV) emitted at $256 \mathrm{eV}$ from the back surface was imaged and time-integrated. ${ }^{30,31}$ The radiation was focused using a spherical multilayer mirror (with a C-WC-Monel-W formulation) onto a Princeton Instruments 16-bit charge coupled device (CCD). The magnification was 12 , and the spatial resolution was $10 \mu \mathrm{m}$. A series of XUV images were obtained in which the image shows a ring structure with a size of $148 \mu \mathrm{m}$. The vertical lineout shows very clearly that this ring structure is real and distinct. This was observed in all types of targets. In Fig. 4, an image and its accompanying lineout from a $\mathrm{CH}-\mathrm{Al}-\mathrm{CH}$ target are shown.

There is very good agreement between the theoretical predictions and the experimental observations, at least in qualitative terms. In quantitative terms, the largest difference is the diameter of the ring feature. The experimentally observed images show a ring feature with a diameter of $100-150 \mu \mathrm{m}$, whereas the synthetic image shows a ring with a diameter of only $50 \mu \mathrm{m}$. Although this is a noticeable discrepancy, it is easy to identify a number of points in the complex multi-stage numerical model that could give rise to this discrepancy. One simple point, for example, is the accuracy of fitting the temperature profile from the fast electron transport simulation. Another is reproducing the exact energy distribution within the focal spot. We therefore believe that increasingly accurate analysis will reconcile the difference between the theoretical predictions and the experimental results.

In order to gain a better understanding of the impact of uncertainties in the temperature and focal spot profile, we performed a parameter scan using a less computationally expensive version of our synthetic diagnostic using axisymmetric 1-D radiation-hydrodynamics calculations instead of the 2-D calculations. We used the 1-D radiation-hydrodynamics code $\mathrm{Hyades}^{27}$ to generate 1-D temperature and density profiles in a range of time intervals and then converted these to 2-D (r,z) data. These data were then post-processed using SPECT3D in the same way as before to generate the expected time-integrated XUV emission images. A range of hot-spot radii, temperatures, and spatial geometries were explored. Figure 5 shows one of the results of these calculations, which shows much better quantitative agreement with the experiment. Here, the diameter of the ring-like XUV emission features is $106 \mu \mathrm{m}$. The initial hot-spot here has a Gaussian spatial structure with a FWHM of $60 \mu \mathrm{m}$ and a peak on-axis temperature of $2 \mathrm{keV}$. It may be noted that the 


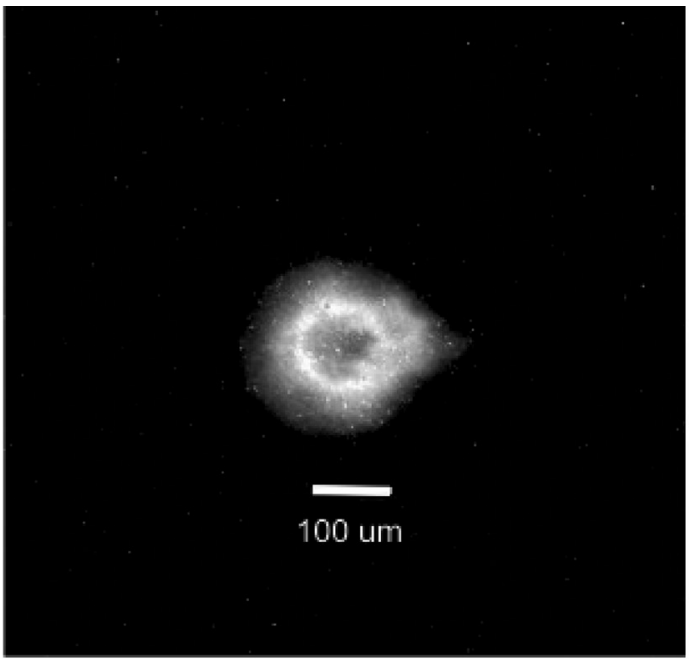

(a)

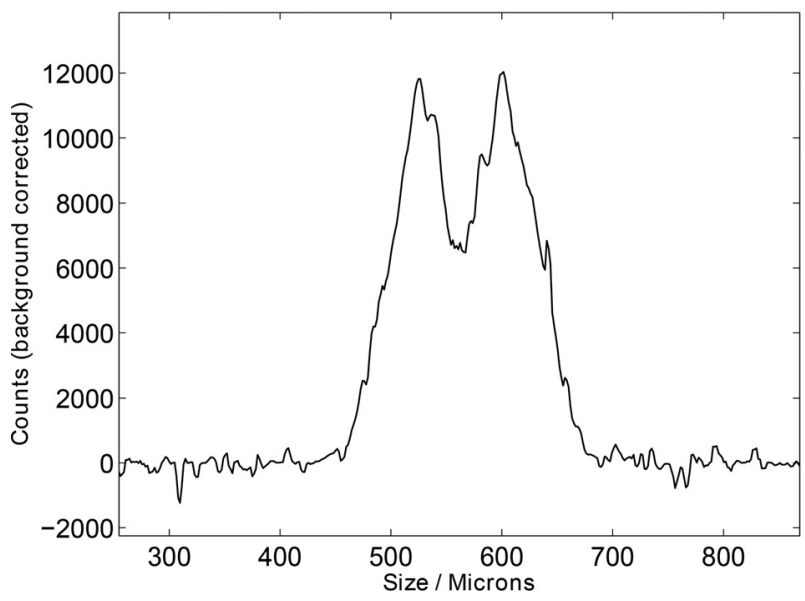

(b)

FIG. 4. (a) Time-integrated XUV image obtained by imaging the rear surface emission of a $\mathrm{CH}-\mathrm{Al}-\mathrm{CH}$ target showing a clear ring pattern. (b) Lineout of this time-integrated XUV image showing the actual signal height of ring relative to the centre.

"hollowed-out" effect in the ring-like XUV emission is significantly less pronounced in these calculations as compared to the original calculations. This is due to the use of 1-D rather than 2-D radiation-hydrodynamics calculations which results in a greater optical depth on axis.

On the basis of the simulations that have been performed, we are confident in claiming that the shock wave inferred from the XUV image had a pressure in excess of 100 Mbar.

Measurements were also taken from $\mathrm{CH}-\mathrm{Al}-\mathrm{CH}$ layers with a thicker front $\mathrm{CH}$ layer $(8 \mu \mathrm{m}, 30 \mu \mathrm{m}$, and $60 \mu \mathrm{m})$. A faint ring pattern could be observed in the target with an $8 \mu \mathrm{m}$ front layer but not in the case of a $30 \mu \mathrm{m}$ front layer. In order to make similar observations in such thick targets, one would need columnar heating right up to the rear surface. However, this would require a well collimated fast electron flow, and in $\mathrm{CH}$, this will only be possible if the fast electron divergence half-angle (i.e., the characteristic half-angle of the fast electron population at absorption) is less than the $30^{\circ}$ half-angle. ${ }^{32}$ This emerges from both fast electron transport

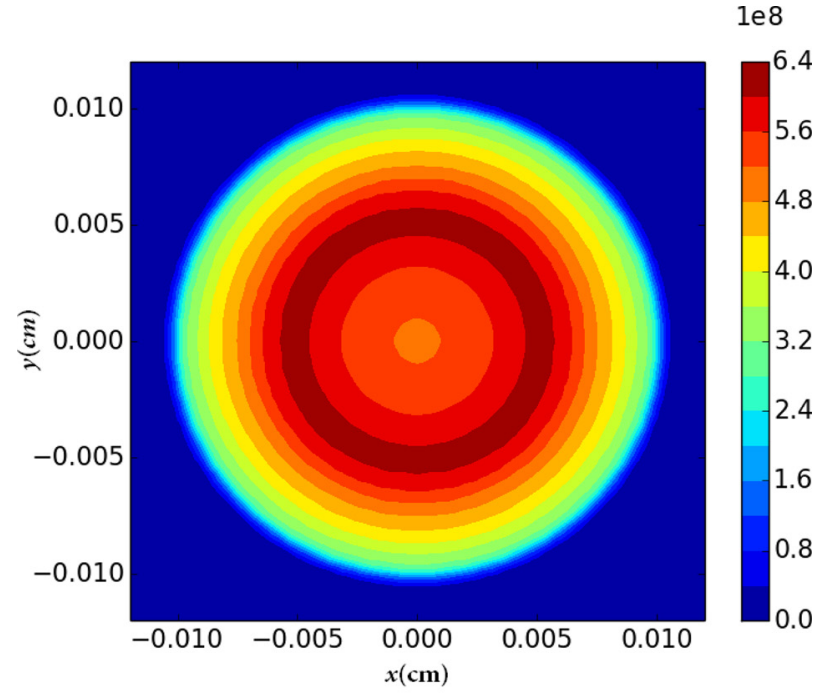

(a)

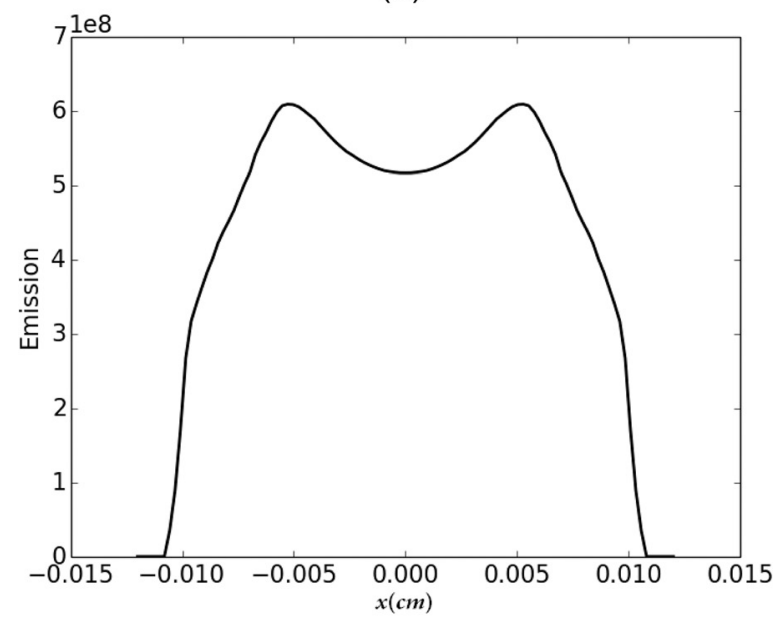

(b)

FIG. 5. (a) A synthetic time-integrated XUV image obtained using the SPECT3D code from initial conditions in the 1-D radiation hydrodynamics calculations of Gaussian temperature profile HWHM of $30 \mu \mathrm{m}$ peaking at $2 \mathrm{keV}$ (color scale is in arbitrary units) and (b) line out of the synthetic timeintegrated image shown in (a).

simulations and more basic criteria, such as the BellKingham condition. ${ }^{33}$ Therefore, the loss of the ring feature in these thicker targets is simply an indicator of the expected divergence in the fast electron flow. We also note that experiments carried out with pure $\mathrm{Al}$ foils do not exhibit the same time-integrated XUV emission patterns; ${ }^{31}$ however, it is unlikely that the same XUV emission pattern would be predicted by the composite numerical model due to differences in fast electron propagation, radiative cooling, and opacity.

It is likely that the effects studied in this paper have been observed in previous experiments, although on all previous experiments that report such annular XUV patterns, the observation has been attributed to other mechanisms. For example, the observations of ring-patterns in XUV images obtained by both Lancaster et al. ${ }^{34}$ and Koch et al. ${ }^{35}$ are attributed to the disruption of the fast electron propagation by the Weibel instability. In the case of Lancaster's results, the similarity in target design and laser parameters means 
that those results can be directly attributed to the mechanisms that we describe in this paper.

This work is important to understanding the collimation of fast electrons through various schemes and how this impacts the heating of matter, especially material tens or hundreds of microns away from the interaction. This technique could therefore be used as a test of fast electron collimation strategies $22,36,37$ to complement the standard approach of measuring $\mathrm{K}$-alpha $\mathrm{x}$-ray emission.

\section{CONCLUSIONS}

In conclusion, we have described through a combination of XUV imaging and numerical modelling measurements consistent with the formation of strong cylindrical shock wave solid targets irradiated by a PW laser launched by rapid fast electron heating. Detailed numerical modelling indicated that the shock wave should be observable as a ring-like feature in time-integrated XUV images when it is at a strength of around 200 Mbar. This corresponded to an experiment that was carried out in which these ring-like patterns were very clearly observed in the XUV images. Such features are not observed in thicker targets because of divergence in the fast electron flow. Apart from the ability to produce images of plasma behaviour that is extremely difficult to directly observe, the methodology that has been employed here could be used as a test of fast electron collimation strategies. Given the early stage of development of the synthetic XUV diagnostic and the complexity of the chain of numerical calculations it requires, it is unsurprising that agreement to the experiment is qualitative. On the basis of parameter scans using 1-D radiation hydrodynamics calculations postprocessed using SPECT3D, it was possible to reproduce the experimental XUV ring emission size more closely by making the initial temperature distribution more experimentally realistic.

\section{ACKNOWLEDGMENTS}

This work was supported by the UK Engineering and Physical Sciences Research Council and the Science and Technology Facilities Council. American colleagues acknowledge support from the U.S. Department of energy Contract Nos. W-7405-Eng-48 and DE-FC52-08NA28302. We also acknowledge additional support from the Japan Society for the Promotion of Science and the Daiwa Anglo-Japanese Foundation. A.P.L.R. is grateful for the use of computing facilities provided by STFC's e-Science facility. P.H. acknowledges support from the Nevada System of Higher Education. J.P. would like to acknowledge the support of the HiPER Project. The authors acknowledge the support of the CLF staff.

${ }^{1}$ S. Campana, V. Mangano, A. J. Blustin, P. Brown, D. N. Burrows, G. Chincarini, J. R. Cummings, G. Cusumano, M. Valle, D. Malesani, P. Mészáros, J. A. Nousek, M. Page, T. Sakamoto, E. Waxman, B. Zhang, Z. G. Dai, N. Gehrels, S. Immler, F. E. Marshal, K. O. Mason, A. Moretti, P. T. O'Brien, J. P. Osborne, K. L. Page, P. Romano, P. W. A. Roming, G. Tagliaferri, L. R. Cominsky, P. Giommi, O. Godet, J. A. Kennea, H. Krimm, L. Angelini, S. D. Barthelmy, P. T. Boyd, D. M. Palmer, A. A. Wells, and N. E. White, Nature 442, 1008 (2006).
${ }^{2}$ M. Megevand, M. Anderson, J. Frank, E. W. Hirschmann, L. Lehner, S. L. Liebling, P. Motl, and D. Neilsen, Phys. Rev. D 80, 024012 (2009).

${ }^{3}$ M. Medvedev and A. Loeb, Astrophys. J. 526, 697 (1999).

${ }^{4}$ G. Gregori, A. Ravasio, C. D. Murphy, K. Schaar, A. Baird, A. R. Bell, A. Benuzzi-Mounaix, R. Bingham, C. Constantin, R. P. Drake, M. Edwards, E. T. Everson, C. D. Gregory, Y. Kuramitsu, W. Lau, J. Mithen, C. Niemann, H.-S. Park, B. A. Remington, B. Reville, A. P. L. Robinson, D. D. Ryutov, Y. Sakawa, S. Yang, N. C. Woolsey, M. Koenig, and F. Miniati, Nature 481, 480 (2012).

${ }^{5}$ J. H. Nuckolls, Nature 239, 139 (1972).

${ }^{6}$ R. Betti, C. D. Zhou, K. S. Anderson, L. J. Perkins, W. Theobald, and A. A. Solodov, Phys. Rev. Lett. 98, 155001 (2007).

${ }^{7}$ M. Tabak, J. Hammer, M. E. Glinsky, W. L. Kruer, S. C. Wilks, J. Woodworth, E. M. Campbell, M. D. Perry, and R. J. Mason, Phys. Plasmas 1, 1626 (1994).

${ }^{8}$ B. A. Remington, R. P. Drake, and D. D. Ryutov, Rev. Mod. Phys. 78, 755 (2006).

${ }^{9}$ R. P. Drake, S. G. Glendinning, K. Estabrook, B. A. Remington, R. McCray, R. J. Wallace, L. J. Suter, T. B. Smith, J. R. A. London III, and E. Liang, Phys. Rev. Lett. 81, 2068 (1998).

${ }^{10}$ M. Koenig, B. Faral, J. M. Boudenne, D. Batani, A. Benuzzi, S. Bossi, C. Rémond, J. P. Perrine, M. Temporal, and S. Atzeni, Phys. Rev. Lett. 74 2260 (1995).

${ }^{11}$ D. Batani, A. Balducci, D. Beretta, A. Bernardinello, T. Löwer, M. Koenig, A. Benuzzi, B. Faral, and T. Hall, Phys. Rev. B 61, 9287 (2000).

${ }^{12}$ R. G. Evans, E. L. Clark, R. T. Eagleton, A. M. Dunne, R. D. Edwards, W. J. Garbett, T. J. Goldsack, S. James, C. C. Smith, B. R. Thomas, R. Clarke, D. J. Neely, and S. J. Rose, Appl. Phys. Lett. 86, 191505 (2005).

${ }^{13}$ M. J. Edwards, J. Phys. Conf. Ser. 688, 012017 (2016).

${ }^{14}$ R. Kodama, P. A. Norreys, K. Mima, A. E. Dangor, R. G. Evans, H. Fujita, Y. Kitagawa, K. Krushelnick, T. Miyakoshi, N. Miyanaga, T. Norimatsu, S. J. Rose, T. Shozaki, K. Shigemori, A. Sunahara, M. Tampo, K. A. Tanaka, Y. Toyama, T. Yamanaka, and M. Zepf, Nature 412, 798 (2001).

${ }^{15}$ M. Tabak, D. S. Clark, S. P. Hatchett1, M. H. Key, B. F. Lasinski, R. A. Snavely, S. C. Wilks, R. P. J. Town, R. Stephens, E. M. Campbell, R. Kodama, K. Mima, K. A. Tanaka, S. Atzeni, and R. Freeman, Phys. Plasmas 12, 057305 (2005).

${ }^{16}$ I. A. Bush, A. P. L. Robinson, R. Kingham, and J. Pasley, Plasma Phys. Controlled Fusion 52, 125007 (2010).

${ }^{17}$ K. U. Akli, S. B. Hansen, A. J. Kemp, R. R. Freeman, F. N. Beg, D. C. Clark, S. D. Chen, D. Hey, S. P. Hatchett, K. Highbarger, E. Giraldez, J. S. Green, G. Gregori, K. L. Lancaster, T. Ma, A. J. MacKinnon, P. Norreys, N. Patel, J. Pasley, C. Shearer, R. B. Stephens, C. Stoeckl, M. Storm, W. Theobald, L. Woerkom, R. Weber, and M. H. Key, Phys. Rev. Lett. 100, 165002 (2008)

${ }^{18}$ J. R. Davies, Phys. Rev. E 68, 056404 (2003).

${ }^{19}$ J. J. MacFarlane, I. E. Golovkin, P. Wang, P. R. Woodruff, and N. A. Pereyra, High Energy Density Phys. 3, 181 (2007).

${ }^{20}$ A. P. L. Robinson, H. Schmitz, and J. Pasley, Phys. Plasmas 20, 122701 (2013).

${ }^{21}$ S. Kar, A. P. L. Robinson, D. C. Carroll, O. Lundh, K. Markey, P. McKenna, P. Norreys, and M. Zepf, Phys. Rev. Lett. 102, 055001 (2009).

${ }^{22}$ B. Ramakrishna, S. Kar, A. Robinson, D. J. Adams, K. Markey, X. M. N. Quinn, P. McKenna, K. L. Lancaster, J. S. Green, R. H. H. Scott, P. A. Norreys, J. Schreiber, and M. Zepf, Phys. Rev. Lett. 105, 135001 (2010).

${ }^{23}$ J. R. Davies, Phys. Rev. E 65, 026407 (2002).

${ }^{24}$ M. Nakatsutsumi, J. R. Davies, R. Kodama, J. S. Green, K. L. Lancaster, K. U. Akli, F. N. Beg, S. N. Chen, D. Clark, R. R. Freeman, C. D. Gregory, H. Habara, R. Heathcote, D. S. Hey, K. Highbarger, P. Jaanimagi, M. H. Key, K. Krushelnick, T. Ma, A. MacPhee, A. J. MacKinnon, H. Nakamura, R. B. Stephens, M. Storm, M. Tampo, W. Theobald, L. V. Woerkom, R. L. Weber, M. S. Wei, N. C. Woolsey, and P. A. Norreys, New J. Phys. 10, 043046 (2008).

${ }^{25}$ W. Theobald, K. Akli, R. Clarke, J. A. Delettrez, R. R. Freeman, S. Glenzer, J. Green, G. Gregori, R. Heathcote, N. Izumi, J. A. King, J. A. Koch, J. Kuba, K. Lancaster, A. J. MacKinnon, M. Key, C. Mileham, J. Myatt, D. Neely, P. A. Norreys, H.-S. Park, J. Pasley, P. Patel, S. P. Regan, H. Sawada, R. Shepherd, R. Snavely, R. B. Stephens, C. Stoeckl, M. Storm, B. Zhang, and T. C. Sangster, Phys. Plasmas 13, 043102 (2006).

${ }^{26}$ J. S. Green, V. M. Ovchinnikov, R. G. Evans, K. U. Akli, H. Azechi, F. N. Beg, C. Bellei, R. R. Freeman, H. Habara, R. Heathcote, M. H. Key, J. A. King, K. L. Lancaster, N. C. Lopes, T. Ma, A. J. MacKinnon, K. Markey, 
A. McPhee, Z. Najmudin, P. Nilson, R. Onofrei, R. Stephens, K. Takeda, K. A. Tanaka, W. Theobald, T. Tanimoto, J. Waugh, L. Woerkom, N. C. Woolsey, M. Zepf, J. R. Davies, and P. A. Norreys, Phys. Rev. Lett. 100, 015003 (2008).

${ }^{27}$ h2d and Hyades are commercial products of Cascade Applied Sciences, email: larsen@casinc.com.

${ }^{28}$ C. N. Danson, P. A. Brummitt, R. J. Clarke, J. L. Collier, B. Fell, A. J. Frackiewicz, S. Hancock, S. Hawkes, C. Hernandez-Gomez, P. Holligan, M. H. R. Hutchinson, A. Kidd, W. J. Lester, I. O. Musgrave, D. Neely, D. R. Neville, P. A. Norreys, D. A. Pepler, C. J. Reason, W. Shaikh, T. B. Winstone, R. W. W. Wyatt, and B. E. Wyborn, Nucl. Fusion 44, S239 (2004).

${ }^{29}$ I. Musgrave, A. Boyle, D. Carroll, R. Clarke, R. Heathcote, M. Galimberti, J. Green, D. Neely, M. Notley, B. Parry, W. Shaikh, T. Winstone, D. Pepler, A. Kidd, C. Hernandez-Gomez, and J. Collier, Appl. Opt. 46, 6978 (2007).

${ }^{30}$ P. Gu, B. Zhang, M. H. Key, S. P. Hatchett, T. Barbee, R. R. Freeman, D. K. Akli, J. A. King, A. J. Mackinnon, R. A. Snavely, and R. B. Stephens, Rev. Sci. Instrum. 77, 113101 (2006).

${ }^{31}$ T. Ma, A. G. MacPhee, M. H. Key, S. P. Hatchett, K. U. Akli, T. W. Barbee, C. D. Chen, R. R. Freeman, J. A. King, A. Link, A. J. Mackinnon,
D. T. Offermann, V. Ovchinnikov, P. K. Patel, R. B. Stephens, L. Woerkom, B. Zhang, and F. N. Beg, Rev. Sci. Instrum. 79, 093507 (2008).

${ }^{32}$ K. L. Lancaster, J. S. Green, D. S. Hey, K. U. Akli, J. R. Davies, R. J. Clarke, R. R. Freeman, H. Habara, M. H. Key, R. Kodama, K. Krushelnick, C. D. Murphy, M. Nakatsutsumi, P. Simpson, R. Stephens, C. Stoeckl, T. Yabuuchi, M. Zepf, and P. A. Norreys, Phys. Rev. Lett. 98, 125002 (2007).

${ }^{33}$ A. R. Bell and R. J. Kingham, Phys. Rev. Lett. 91, 035003 (2003).

${ }^{34}$ K. L. Lancaster, M. Sherlock, J. S. Green, C. D. Gregory, P. Hakel, K. U. Akli, F. N. Beg, S. N. Chen, R. R. Freeman, H. Habara, R. Heathcote, D. S. Hey, K. Highbarger, M. H. Key, R. Kodama, K. Krushelnick, H. Nakamura, M. Nakatsutsumi, J. Pasley, R. B. Stephens, M. Storm, M. Tampo, W. Theobald, L. Woerkom, R. L. Weber, M. S. Wei, N. C. Woolsey, T. Yabuuchi, and P. A. Norreys, Phys. Rev. E 80, 045401 (2009).

${ }^{35}$ J. A. Koch, M. H. Key, R. R. Freeman, S. P. Hatchett, R. W. Lee, D. Pennington, R. B. Stephens, and M. Tabak, Phys. Rev. E 65, 016410 (2001).

${ }^{36}$ A. P. L. Robinson and M. Sherlock, Phys. Plasmas 14, 083105 (2007).

${ }^{37}$ A. P. L. Robinson, H. Schmitz, J. S. Green, C. P. Ridgers, and N. Booth, Plasma Phys. Controlled Fusion 57, 064004 (2015). 